\title{
SUPERAR LA UTOPÍA: CARIDAD CRISTIANA Y PRUDENCIA EN LA ACCIÓN POLÍTICA
}

\author{
Cristóbal Orrego S. \\ Profesor de Filosofía Jurídica y Política \\ Universidad de los Andes \\ Pontificia Universidad Católica de Chile
}

Toda utopía política promete el paraíso en la tierra y solamente consigue violentar la naturaleza de la convivencia humana. Una adecuada ética política no puede ser utópica. Dos virtudes permiten superar la utopía: la caridad cristiana, que en el plano de las relaciones humanas es una superelevación de la amistad, y la prudencia. La caridad, en primer lugar, constituye el motor de actuaciones políticas desinteresadas, pues lleva a buscar en cada circunstancia de la vida el bien de los demás, por amor a Dios. La amistad como virtud humana consiste esencialmente en la benevolencia hacia los demás, no motivada explícitamente por el amor a Dios (aunque los cristianos creemos que la gracia de la caridad opera de modo secreto en los corazones de los hombres de buena voluntad que sin culpa suya desconocen la verdadera fe divina). El amor llevado a la política rescata el atractivo que toda utopía encierra en cuanto promesa del cielo. La prudencia, en segundo término, dirige todas las acciones con el realismo necesario para su eficacia. Esta virtud hace posible una política acomodada pragmáticamente a las circunstancias de tiempo, lugar y personas. En este ensayo procuraremos exponer las exigencias básicas de la caridad cristiana y de la prudencia como virtudes aplicadas a la acción política de los políticos no gobernantes. Lo que se diga acerca de la caridad cristiana vale, mutatis mutandis, a las exigencias de la amistad o amor de benevolencia en un plano no cristiano de rectitud ética natural.

\section{La caridad en general ${ }^{1}$}

La caridad es la más excelente de las virtudes cristianas" ${ }^{2}$ y se define como "una virtud teologal infundida por Dios en la voluntad, por la que amamos a Dios por sí mismo sobre todas las cosas y a nosotros y al prójimo por Dios" ${ }^{3}$. En cuanto la política

\footnotetext{
1 La caridad es virtud teologal, de modo que sólo puede adquirirse por la gracia de Dios. Sin embargo, aunque no forme parte de las exigencias naturales que pueden hacerse a todos los hombres con independencia de cuál sea su fe religiosa, resulta una cualidad admirable de los verdaderos cristianos, y en este trabajo se considera no sólo la moral natural, sino también la moral sobrenatural. Por otra parte, aunque la caridad cristiana es necesaria por sí misma y distinta de la solidaridad humana, no debe perderse de vista que la solidaridad y la amistad social valen como virtudes humanas — virtudes anejas a la justicia - y son un presupuesto de la virtud teologal. Sobre el amor como virtud moral natural, puede verse Marcel Reding: Fundamentos Filosóficos de la Teología Moral Católica (Madrid, Rialp, 1964) pp. 121-122; E. Welty: Catecismo Social (Barcelona, Herder, 1956) pp. 270 y ss.

2 Santo Tomás la llama "radix omnium virtutum" ("raiz de todas las virtudes" S.Th., 1-1I, q. 62, art. 4, resp.)

3 Antonio Royo Marín: ITeología Moral para Seglares. Moral Fundamental y Especial (Madrid, Bac, 5a. ed., 1979 ) p. 262.
} 
es una actividad interpersonal, nos interesa estudiar la caridad que debe practicar el político con su prójimo ${ }^{4}$, particularmente con los otros profesionales de la política.

Las consideraciones subsiguientes suponen, como es lógico, un cristiano dedicado a la actividad política, que desea practicar las exigencias de la caridad como condición necesaria para santificar esa profesión humanamente noble. Por analogía pueden aplicarse estas reflexiones al orden del amor natural, de la benevolencia y misericordia que cualquier hombre honrado, aun sin la fe, puede imitar en alguna medida.

El político debe procurar en medio de sus actuaciones ver personas en sus interlocutores y, desde el punto de vista sobrenatural, hijos de Dios. Por tanto, ha de cultivar un amor interno que se manifieste exteriormente; no bastan los buenos deseos: hay que desear y hacer el bien al prójimo. Del mismo modo, no son suficientes las actitudes meramente exteriores de afecto sin un verdadero esfuerzo interior de comprensión; se trataría de un cálculo hipócrita o -en el mejor de los casos- de una simple técnica política de buenas relaciones.

Desear el bien para los demás presenta dificultades especiales en relación con aquellos hombres que se presentan como enemigos o que objetivamente actúan mal en la vida pública. A los enemigos - quienes nos injurian, nos odian o se hacen dignos de un justo reproche por su conducta inmoral- se les debe amar en cuanto hombres. Por eso, no es lícito el odio de enemistad, que lleva a desear algún mal en cuanto tal; en cambio, sería aceptable desear algún mal puramente relativo exigido por el bien objetivo de esas personas o por el bien común. Así, por ejemplo, es lícito desear que un individuo sea removido de su cargo, o que pierda en una elección popular, o que reciba un castigo justo para proteger a los afectados, etc.

Tampoco puede aceptarse el deseo de venganza, que lleva a buscar principalmente el mal de una persona culpable y a gozarse en él. Sin embargo, es lícito pedir a la autoridad pública el castigo del delincuente, siempre que se deponga todo odio y se busque sólo el bien del mismo culpable y de la sociedad, como consecuencia de la reparación del derecho. Desde el punto de vista de la decisión política en cuanto a castigar a los culpables, debe tenerse en cuenta que la pena es una exigencia del bien común tanto como de la justicia conmutativa; por lo tanto, sólo es lícito renunciar a la imposición de la pena cuando de ese perdón (amnistía o indulto) se deriven beneficios mayores para la sociedad que del cumplimiento estricto de la ley.

Las exigencias de la caridad en el terreno político son altas. Al contrincante incluso cuando nos insulte en un debate, o nos odie por cualquier motivo, etc. - se le debe manifestar amistad y afecto, al menos con los signos comunes, como son el saludo, la buena educación, el diálogo (v.gr., responder a las preguntas que nos efectúe, en cuanto se refieran a cuestiones corrientes y no supongan una injusta averiguación de lo que no tiene derecho a saber), etc. Incluso, si llegara a encontrarse en alguna necesidad sería necesario prestarle una ayuda especial. Más aún: siendo frecuente en la actividad política el enemistarse por ofensas de variada índole, la caridad exige buscar una pronta reconciliación, estando más obligado a tomar la iniciativa el ofensor que el ofendido. Se puede pedir expresamente perdón, aunque normalmente basta con buscar una forma de restablecimiento implícito de la armonía. Por su parte, el ofendido —aunque no está

${ }^{4}$ Cfr. S. Th. II-HI, q. 66, a, 6, resp. 
obligado strictu sensu - puede tomar la iniciativa de la reconciliación; y, en cualquier caso, debe aceptar la reconciliación que se le ofrece: la obligación de perdonar es grave . En fin, debe tenerse en cuenta que normalmente ambos implicados tienen culpa en el rompimiento de las buenas relaciones. ${ }^{5}$

Las reflexiones anteriores se sitúan ante casos a veces extremos, mas hemos de tener en cuenta que la oposición en el terreno político (ser contrincantes o adversarios) es compatible con la unión en otros ámbitos (amistad personal). La caridad tiende precisamente a proteger los ámbitos de amistad de una injerencia abusiva por parte de los ámbitos de la confrontación (política). La globalización de la contrariedad (religiosa, científica, política, etc.) hasta el punto de imposibilitar una amistad o unión anímica y espiritual personal es una consecuencia obligada de la absolutización de la temporalidad y de los fines temporales. La caridad parte de un presupuesto difícil, pero fecundo y necesario, a saber: que las diferencias en el ámbito temporal son todas relativas en comparación con el fin último trascendente común a todos los hombres. (Esta idea también se aplica a las diferencias religiosas, pues la religión - aun cuando desde el punto de vista lógico sólo pueda haber una plenamente verdadera - también es un ámbito de medios destinados al fin eterno, ámbito que exige más que ninguno el respeto y la unión con los demás codestinatarios).

\section{Las clásicas obras de caridad adaptadas a la acción política ${ }^{6}$}

El ejercicio de las actividades en torno al poder político, y la lucha por conquistarlo, dan ocasión para practicar las obras de caridad, en diversas formas. En rápida enumeración podemos ir viendo algunas de las clásicas obras de misericordia que pueden aplicarse en este campo.

El político siempre es un orador: su palabra llega a multitudes, en defensa de una idea o de un programa, en busca de apoyo popular, etc. Esta palabra debe ser instrumento para enseñar al que no sabe. En buena medida, son los políticos quienes estudian a fondo los problemas públicos, o buscan un prudente asesoramiento de fondo. Si no lo hacen, se genera desconfianza hacia todos los políticos en general. De modo que la caridad con el pueblo exige informarle adecuadamente, enseñarle conforme a la verdad, sin falsear datos ni manipular estadísticas, etc.

La libertad de enseñanza, reconocida casi universalmente como un derecho de la persona humana y de sus comunidades, tiene un campo de aplicación en la formación política, siempre y cuando no se intente utilizar la enseñanza sistemática y regular reconocida oficialmente para propagar tendencias político-partidistas concretas. Además, si la educación tiene por objeto el pleno desarrollo de la persona en las distintas etapas de su vida, el derecho a la educación también se extiende al aspecto político en conformidad con los intereses del educando. Precisamente una de las funciones de los partidos políticos y de los políticos independientes consiste en contribuir a la formación de ciudadanos capacitados para asumir responsabilidades públicas.

También se puede enseñar a los políticos que no saben. En este caso, debe hacerse en primer lugar con aquellos que colaboran en una empresa común (un mismo

${ }^{5}$ Cfr. Royo, op. cit., pp. 383 a 394.

${ }^{6}$ Sobre lo que se expone a continuación, véase Antonio Lanza y Pietro Palazzini: II Principias de Teología Moral. Las Virtudes (Madrid, Rialp, 1958) pp. 500-511, y Royo, op. cit., pp. 394 a 404. 
partido, una campaña o candidatura común, etc.), según el recto orden de la caridad. Pero también convendrá hacerlo con los contrincantes políticos; y será un deber cuando así lo exija la adecuada solución de un problema en el que deben participar todos. No resulta extraño, entonces, que generalmente se reconozca a los ciudadanos (y especialmente a los partidos políticos) la facultad de ejercer la libertad de opinión y el derecho de petición para presentar, ante el público en general y ante las autoridades, iniciativas y criterios de acción frente a los asuntos de interés público.

Otra de las actuaciones de la caridad es dar consejo al que lo necesita. La labor de consejo en política es muy importante precisamente porque se trata de una continua actuación de la prudencia, uno de cuyos actos es el aconsejarse. Los políticos de partido o independientes pueden y deben, por tanto, cooperar mediante su consejo y asesoría con las autoridades que gobiernan. Muy relacionada con esta ayuda se encuentra la de corregir al que yerra. El error práctico o teórico de un político puede tener consecuencias graves para toda la sociedad. Corregirlo es obligación grave que debe cumplirse con la prudencia necesaria para que surta efecto: en privado, oportunamente, con mansedumbre y humildad. Conviene omitir la corrección si se juzga que será contraproducente (por provocar ira, enemistad, etc.). Las denuncias clamorosas del error de un político rara vez lo sacan de él, y contribuyen a disminuir su fama. Hacerlo sólo para obtener ventajas en la lucha por el poder, incluso si la "denuncia" es verdadera, es contrario a la auténtica caridad, que debe primar por sobre una ventaja contingente. La corrección es una ayuda; la difamación, a la larga hace daño a todos los políticos profesionales en su conjunto. Sin embargo, si es previsible que una corrección secreta va a ser inútil, o si el mal causado es público o se hará público, o causa grave daño a terceros, puede denunciarse el mal sin advertencia previa. En estos casos prima el bien común. El ejercicio del derecho de petición, como hemos dicho, constituye un medio útil para aconsejar y, en su caso, corregir a la autoridad.

Aconsejar y aconsejarse resulta especialmente necesario por el carácter opinable de las materias que se tratan, de modo que en este terreno casi siempre subsiste el temor de que la opinión contraria sea la correcta. Un político que tuviera absoluta certeza en sus apreciaciones sobre asuntos contingentes daría muestras no de un conocimiento evidente privilegiado, cosa por lo demás imposible, sino de un gran voluntarismo político en la afirmación de sus propias opciones. Por el contrario, el político prudente aprende a desconfiar moderadamente de su propio criterio y a confiar en el saber de los demás, sometiendo sus conclusiones a una discusión razonable con personas de buena fe de diversas orientaciones políticas.

En la convivencia política los roces continuos dan ocasión de perdonar las injurias y de sufrir con paciencia los defectos de los demás, sabiendo que todos tenemos los propios. Estas realidades - la lucha, las injurias, los ataques personales, etc.- pueden desanimar a personas capaces de intervenir en política. Frente a las "acusaciones de arribismo, de idolatría del poder, de egoísmo y corrupción que con frecuencia son dirigidas a los hombres del gobierno, del parlamento, de la clase dominante, del partido político ${ }^{17}$ y a "la difundida opinión de que la política es un lugar de necesario peligro moral $1{ }^{8}$, puede surgir un comprensible abstencionismo y escepticismo. Sin embargo,

\footnotetext{
7 Juan Pablo II: Christifideles laici, n. 42.

8 Ibidem.
} 
dicha actitud no se justifica en lo más mínimo ${ }^{9}$ y una aplicación actual de la tradicional obra de misericordia consistente en consolar al triste puede ser la de levantar el ánimo a los escépticos. De este modo, la participación de los mejores, tantas veces más difícil de conseguir porque no ambicionan ni el poder ni los honores y porque sienten la repugnancia ante las malas artes de los corruptos, evita que el poder político quede en manos de incapaces y de inescrupulosos.

\section{La caridad expulsada de la política ${ }^{10}$}

En términos generales, hay una serie de actitudes y acciones contrarias a la caridad, de fácil comprensión por cualquiera, pues están presentes en la experiencia política normal.

Desde el punto de vista de su maldad interior, es el odio la peor de las faltas contra el prójimo, y puede ser causa de otros males que son peores desde el punto de vista externo (el homicidio, por ejemplo). El odio lleva a desear el mal al prójimo en cuanto mal, y a entristecerse de su bien en cuanto tal bien del otro. En este sentido se asemeja a la envidia o "tristeza del bien ajeno que se considera como un mal para nosotros, en cuanto que rebaja nuestra gloria y excelencia" ${ }^{11}$.

En política la envidia y el odio se entristecen de que otros, incluso dentro de un mismo sector político, accedan a un cargo, o aumenten su popularidad, etc. Se trata de una actitud vil que impulsa a murmurar, a difamar, a alegrarse en las contrariedades ajenas, etc. Pensemos, por ejemplo, en quienes buscan rebajar a cualquiera que sobresalga un poco en popularidad, o que amenace con captar el apoyo popular para acceder a un cargo.

En el plano de la actividad política normal son frecuentes defectos como la discordia, la contienda y - en casos extremos - la riña.

La discordia es enemiga del legítimo pluralismo de opiniones. En efecto, por naturaleza existe diversidad de opiniones entre los miembros de la comunidad política, pues cada uno tiene sus intereses particulares, un punto de vista peculiar, etc. Sobre la mera política cabe diversidad de opiniones, como enseña el Magisterio de la Iglesia defendiendo la libertad de los católicos en la arena política ${ }^{12}$. Este pluralismo en lo contingente es un bien social, consecuencia de la libertad ${ }^{13}$, y la caridad exige un delicado respeto hacia quienes piensan de un modo distinto.

La concordia es uno de los efectos de la caridad ${ }^{14}$. La discordia se produce cuando las voluntades no quieren unirse para mantener la concordia y la amistad; es decir, no se acepta la diversidad de opiniones, pues se supedita la amistad a la igualdad en el

9 Ibidem.

${ }^{10}$ Cfr. Lanza-Palazzini, op. cit., tomo II. pp. 63-64; y Royo, op. cit., pp. 404-424.

11 Royo, op. cit., p. 405.

${ }^{12}$ Cfr. Angel Torres Calvo: Diccionario de Textos Sociales Pontificios (Madrid, Compañía Bibliográfica Española, $2^{3}$ ed., 1962) p. 1501.

13 Sobre el pluralismo en orden al bien común, cfr. José Miguel lbáñez Langlois: Doctrina Social de la Iglesia (Santiago. Ed. Universidad Católica, $1^{2}$ ed., 1986) pp. 30-31; Johannes Messner, Etica Social, Política y Económica a la luz del Derecho Natural (Madrid, Rialp, 1969) pp. 838-844.

${ }^{14}$ S. Th., IIII, q. 29, a. 3. 
pensamiento. Paulatinamente puede llegarse a la discusión violenta con las palabras, especialmente en los debates, declaraciones o intercambio de correspondencia pública o privada. La contienda se preocupa más de vencer al adversario que de averiguar la verdad. Especialmente grave resulta cuando llega a sacrificar la verdad conocida negándola - con tal de no ceder en la discusión. En la vida política se destruye, por esta vía, la confianza en el diálogo como medio de ordenar la acción individual hacia el bien común.

Finalmente, en el colmo de la efervescencia política puede llegarse a la riña o pelea física ${ }^{15}$. Los golpes o heridas, cuando son efecto de acciones políticas, constituyen un síntoma claro de decadencia social: la política deja de ser actividad de la razón en torno al poder, como medio, dirigida al bien común, y se transforma en mero escenario de las pasiones por el poder.

En cualquier caso, el agredido siempre puede defenderse con moderación. En casos extremos, será incluso un deber utilizar la fuerza para impedir que la política sea un coto cerrado de violentistas. Todo lo anterior se entiende en cuanto sea una aplicación de los principios morales y de las normas legales que reconocen el derecho (y frecuentemente el deber) de la legítima defensa propia y ajena. Sin embargo, lo normal es que estas situaciones puedan ser evitadas o sancionadas recurriendo a los medios legales ordinarios.

Estos extremos reseñados no pueden tolerarse so pretexto de pluralismo. Garantizar el pluralismo político incluye proscribir todas las conductas que atenten contra ese pluralismo (de lo contrario se garantiza todo menos el pluralismo en cuanto tal). Sin embargo, es una cuestión prudencial determinar los medios legales concretos más adecuados para proteger el pluralismo (v.gr., utilizar sólo la ley penal común o, además, establecer mecanismos de proscripción de partidos o ideologías, como sucede en países como Alemania o Chile). La protección del pluralismo político es una exigencia moral. Las vivas polémicas sobre algunos mecanismos concretos, como la proscripción o no de partidos, no afectan al principio ético general. Más aún, tratándose de una discusión sobre una solución opinable de derecho positivo, las opiniones contradictorias son, a nuestro juicio, igualmente legítimas. Lo que importa, en el fondo, más que el mecanismo utilizado es que se reconozca la idea de respetar ciertos valores inherentes a la democracia $^{16}$.

Ahora bien, es necesario insistir en que todas las normas jurídicas que busquen proteger el pluralismo político son de derecho positivo. Aunque puedan tener un fundamento remoto en determinados principios éticos, no se derivan de ellos como conclusiones, sino que son determinaciones voluntarias, políticas, que pueden existir de muchas maneras diversas. Es perfectamente lícita la opinión de que lo prudente es tolerar la propaganda de ideologías erróneas; pero siempre habrá normas protectoras del orden público establecido. La mayor o menor amplitud en la aplicación del príncipio de tolerancia (que en ninguna sociedad es absoluta respecto de todos los aspectos de la vida común, pues eso equivaldría a la ausencia de toda prohibición y sanción) es una cuestión prudencial y opinable.

\footnotetext{
${ }^{15}$ Vèase J. Mausbach-G. Ermecke: III Teología Moral Católica (Pamplona, Eunsa, 1974) pp. 217-218.

${ }^{16}$ Cfr. Hernán Larraín Fernández: Ideología y Democracia en Chile (Santiago, Ed. Andante, 1988) p. 136.
} 
Los siguientes apartados abordan cuestiones relativas a la prudencia, a su recto sentido como virtud moral esencial para la acción política. La prudencia no es una técnica pragmática; sin embargo, exige y presupone una técnica, por lo cual comenzaremos por investigar las relaciones entre prudencia y técnica.

\section{La prudencia del político y la técnica ${ }^{17}$}

Toda acción política supone un conocimiento del fin que se intenta, de las circunstancias concretas en las cuales debe lograrse tal fin y de los medios disponibles. La prudencia es la virtud intelectual que delibera y escoge los medios convenientes con vistas al fin ${ }^{18}$. La acción política procede de la prudencia política. La razón práctica ordena los medios hacia el fin teniendo en cuenta que se trata de obrar bien desde el punto de vista del efecto inmanente de la operación; es decir, a la prudencia interesa hacer el bien desde el punto de vista moral, de modo que de la conducta del agente se derive para él un bien en sentido absoluto, y no sólo una utilidad técnica. Desde el punto de vista social, "la vida política aspira a un bien común, superior a una mera colección de bienes individuales, y que sin embargo debe remitirse siempre a las personas humanas"119. En definitiva, la prudencia política se propone un fin de carácter ético: el bien común. Por eso afirma Santo Tomás: "por cuanto a la prudencia corresponde deliberar rectamente, juzgar e imperar acerca de las cosas necesarias en orden al fin debido, resulta evidente que la prudencia no sólo se orienta al bien privado de un solo hombre, sino también al bien común de la multitud" ${ }^{20}$

Evidentemente, la misma prudencia exige que se ordenen los medios al fin de un modo técnicamente eficaz: el político que sólo tiene unas ideas vagas, unos ideales utópicos o un discurso "moralizante" pero poco práctico, no sirve al bien común; en cambio, si adquiere los conocimientos técnicos necesarios para opinar y -en su casopara dirigir el acontecer social con efectividad, sin demagogia, se constituye en un verdadero "político prudente". No existe una contraposición entre el "hombre técnico" y el "hombre político", porque entre el arte o técnica y la prudencia (como virtud moral) existe una complementariedad natural, por la subordinación del primero a la segunda. La técnica (sea o no política) presta su ayuda al político; pero ser un buen técnico no exige poseer la prudencia política. Por el contrario, ser un buen político exige no sólo poseer la prudencia política, sino también, y a cabalidad, la técnica política de usar y dirigir los medios externos hacia los fines propuestos. Además, el político prudente debe actuar conforme a las reglas propias de los otros ámbitos y de las otras artes que le toca orientar hacia el bien común. En este sentido, debe conocer la economía, la educación, la agricultura, la prensa, las actividades de defensa y seguridad, el deporte, etc., desde un punto de vista técnico global. No es necesario que sea un técnico en todas las materias, sino solamente que tenga la prudencia de respetar las leyes intrínsecas que rigen estas áreas sociales, sabiendo escuchar los consejos de quienes dominan la respectiva técnica.

\footnotetext{
${ }^{17}$ Cfr. Royo, op. cit., pp. 352 a 356.

${ }^{18}$ Cfr. Etienne Gilson, El Tomismo. Introducción a la Filosofía de Santo Tomás de Aquino (Pamplona، Eunsa, 1978) p. 467.

19 Jacques Maritain, en Donald e Idella Gallagher (eds.):Lecturas Escogidas de Jacques Maritain (Santiago, Ed. Nueva Universidad, Universidad Católica de Chile, 1974) p. 196.

${ }^{20}$ S. Th., II-II, q. 47 , a. 10 , resp.
} 
Si no existe tal contraposición entre la técnica y la política, ¿a qué se debe ese protagonismo en el desprestigio que afecta a políticos y técnicos de modo alternativo? ¿Por qué existe una impresión popular de oposición entre hombres técnicos y hombres "políticos"? Quizá puede encontrarse una respuesta en el adagio clásico "corruptio optimi, pesima" ("la corrupción de lo mejor es lo peor"). En efecto, el desprestigio procede precisamente de no guardar la armonía entre la técnica y la política.

La técnica, cuando olvida su subordinación a la prudencia ${ }^{21}$, se erige en norma de gobierno y reduce todo el pluralismo de realidades sociales a una dimensión parcial. En otras palabras, no se orientan cabalmente todos los bienes particulares al bien común; sino que se someten las realidades particulares a un ámbito particular también, con lo cual se resiente el bien común. Se desvirtúa, entonces, la naturaleza misma de la acción política, pues "la decisión política implica una visión global de los asuntos públi$\cos y$, por tanto, debe ser ejercida por un gobierno que no sea la suma de muchas visiones parciales" 22 .

La tiranía de la técnica resulta tanto más grave cuanto más particular sea el ámbito hegemónico, pues implica un reduccionismo mayor. Esto ocurre, por ejemplo, cuando se trata de aplicar la racionalidad económica en forma absoluta. La tecnocracia económica supone, muchas veces, un reduccionismo materialista, o cuando menos cierto positivismo; sin embargo, puede mostrar algunos éxitos precisamente porque todas las actividades humanas - hasta las más espirituales- requieren un apoyo material. Particularmente exitosa se muestra cuando se encuentra en decadencia el nivel general de la cultura y de la vida espiritual en la sociedad. En este caso, el reduccionismo materialista concuerda con la claudicación ética del hedonismo consumista.

Pueden imaginarse otros modos más graves de supremacía técnica: la del dominio policial o militar que sofoque las libertades religiosas, civiles y económicas; la tiranía cultural en que una visión particular de la cultura o una ideología se impone por fuerza a la libertad ciudadana, a veces con sutiles controles sobre los medios de comunicación y los programas y métodos de educación de la juventud; etcétera.

Todos estos males son una consecuencia casi necesaria, a mi modo de ver, del pensamiento moderno que reduce lo cualitativo (ámbito de la prudencia) a lo cuantitativo (ámbito de la técnica) y que niega - como ocurre en el liberalismo- la posibilidad de un bien social común (consecuencia de la negación epistemológica de la posibilidad de una objetividad común), reduciéndolo a la articulación mecánica de diversos bienes y objetivos particulares. Natural resulta, entonces, que la economía (principalmente) adquiera primacía en el ordenamiento social, y se intente reconducir a su lógica el derecho, la política, la religión, la moral, etc.

Sin embargo, del mismo modo que la prudencia es superior al arte, la corrupción de la técnica es menos mala que la corrupción de la política. Una política que desprecia la técnica se demuestra tarde o temprano ineficaz. La demagogia fundamenta el éxito de la acción política no en hechos concretos de contribución al bien común, sino en el discurso ideológico brillante - a veces conmovedor- pero poco práctico. Esta situa-

\footnotetext{
${ }^{21}$ Sobre la primacía de la política, véase Messner, Etica Social .... pp. 956-958.

22 Jaime Guzmán, en Actas Oficiales de la Comisión de Estudio de la Nueva Constitución (Santiago, Imp. Gendar Chile، 1977) sesión $27^{3}$, p. 18 ,
} 
ción desprestigia enormemente la actividad política. Sus frutos son peores que los del economicismo u otra forma de supremacía técnica, pues no se dirige ninguna actividad social con efectividad hacia el bien común. Más aún: todas las intervenciones "políticas-no-técnicas" en economía, salud, educación, defensa nacional, policía, deporte, etc., terminan acarreando males particulares en los mismos ámbitos intervenidos, sin sacar de ello un provecho para el bien común. La "política utopista" crea un "mundo político" desconectado del mundo real. Los políticos se sumergen en debates, pactos, campañas, votaciones y discursos altamente ideológicos, a la par que olvidan las necesidades concretas que deben remediar, los medios concretos de que disponen, la realidad contingente que se enfrenta fuera del ámbito de los pasillos de la clase gobernante,

Toda esta problemática se remedia con un poco de auténtica prudencia. A continuación analizamos algunas de sus exigencias, sin olvidar que "lo difícil no es saber en qué consiste la prudencia, sino adquirirla. Es la obra de toda una vida" ${ }^{23}$.

\section{Los elementos integrantes de la prudencia ${ }^{24}$}

"La prudencia es la recta razón sobre lo que se ha de obrar" ${ }^{25}$, y necesita para funcionar a la perfección una suma de varios elementos, los cuales, en materia política, tienen unas especiales cualificaciones y consecuencias.

En el orden político se debe descender al conocimiento de lo contingente, para lo cual se ha de tener en cuenta lo que sucede comúnmente, y esto lo enseña la experien$\mathrm{cia}^{26}$. La acumulación de recuerdos da origen a la experiencia, en sus aspectos positivos y negativos. El recuerdo de la eficacia de un determinado modo de proceder, o de las consecuencias malas de una acción, es un primer antecedente para decidir lo que se ha de hacer en el futuro. La memoria ayuda a decidir con mayor rapidez y a actuar con oportunidad, sabiendo esperar o adelantarse a los acontecimientos según el caso. Por eso, la memoria del pasado es un elemento indispensable en política. Los ordenamientos jurídicos reconocen esta exigencia fundamental del buen gobierno cuando, prudencialmente, determinan una edad mínima para ejercer ciertos cargos públicos. La edad no es garantía de mayor inteligencia, ni de mayor libertad, ni siquiera de virtud; pero sin duda es un requisito necesario (no siempre suficiente) de la experiencia.

Al hablar de prudencia en política se alude a la dirección de la propia conducta en cuanto se obra, en definitiva, para influir sobre el gobierno de la comunidad política. Por tanto, no basta el solo recuerdo individual, útil para buscar el bien propio. Además se requiere un "recuerdo colectivo". El político debe tener en su memoria individual la historia del país y de los acontecimientos políticos en los que él mismo no ha participado. El estudio de la Historia no es solamente una exigencia cultural para el político, sino una necesidad profesional. Si un político ve que determinados partidos han incumplido sus promesas, han recurrido a la violencia, han engañado y difamado a sus adversarios, etc., no puede esperar a ser personalmente víctima de tales conductas para obrar con precaución. Se debe escarmentar en cabeza ajena.

\footnotetext{
${ }^{23}$ Gilson, El Tomismo, p. 505.

24 25 
Se necesita conocer también lo contingente aquí y ahora, en cuanto bueno o malo, conveniente o inconveniente. A través de lo que los clásicos llamaron intellectus o inteligencia de lo presente se capta la realidad por los propios medios ${ }^{27}$. Se trata de una cualidad muy útil en política, de una especie de instinto o intuición para discernir con una sola mirada la bondad o malicia de una acción posible.

Cuando se está frente a un caso práctico de cierta complejidad no basta con una intuición personal para resolverlo, sino que se requiere una reflexión madura, un examen atento de los aspectos positivos y negativos de una decisión. Se llama "razón" a la parte de la prudencia que permite resolver por uno mismo los casos no urgentes ${ }^{28}$. Precisamente en estos casos en que se dispone de tiempo para meditar una respuesta, nadie debe considerarse infalible en juzgar lo contingente, por lo cual es necesario cultivar cierta docilidad para aprovechar la experiencia y sabiduría de otros políticos o de asesores técnicos ${ }^{29}$. Los múltiples organismos asesores que se añaden a los cuerpos propiamente políticos en todos los países, facilitan institucionalmente este aspecto de la prudencia política.

Frente a cuestiones urgentes, cuando la misma prudencia hace ver que no es posible pedir consejo, se requiere prontitud de espíritu o sagacidad para tomar la decisión adecuada y a tiempo ${ }^{30}$. El político que acierta en la mayoría de los casos gracias a su capacidad de reflexión, pero que es incapaz de tomar una decisión rápida en las emergencias, es un profesional incompleto. La sagacidad resulta particularmente útil en los estados de excepción constitucional, entre los que hay que incluir tanto los casos previstos de modo general por las constituciones de los diversos países como el caso excepcionalísimo en que se hace uso del derecho de rebelión armada contra un poder legal ilegítimo en su ejercicio.

Para completar las cualidades del político prudente, debemos incluir la circunspección y la cautela o precaución ${ }^{31}$. En virtud de la primera, se consideran todas las circunstancias que rodean el acto, y que pueden influir en su conveniencia o disconveniencia. Por ejemplo: si un partido político decide que es conveniente proclamar a tal o cual persona como candidato a la Presidencia de la República, y efectivamente es eso lo más prudente, no es indiferente que lo haga hoy o mañana, por la prensa o en un acto masivo, etc. Quizá una proclamación prematura desgaste la candidatura; y si es muy tardía puede captar pocas adhesiones. Todas estas cuestiones dependen de las circunstancias que rodeen el hecho mismo de la proclamación, aun dando por supuesto que la decisión en sí misma sea acertada. Se deben considerar las cosas con circunspección.

Por su parte, la cautela es necesaria para evitar los obstáculos extrínsecos que amenacen el éxito de la empresa. No basta con presentar un adecuado programa de gobierno, sino que es menester mostrar los inconvenientes de los programas o ideologías adversas, siempre dentro del respeto a las personas. Con mayor razón es necesario precaver los atentados contra los derechos cívicos fundamentales, como son las cam-

\footnotetext{
${ }^{27}$ Cfr. S. Th., II-II, q. 49 , a. 2.

${ }^{28}$ Cfr. S. Th., II-II. q. 49, a. 5.

${ }^{29}$ Cfr. S. Th., II-II, q. 49, a. 3.

${ }^{30}$ Cfr. S. Th., II-II, q. 49, a. 4. Santo Tomás llama solertia a esta virtud.

${ }^{31}$ Cfr. S. Th. II-II, q. 49 , aa. 7 y 8.
} 
pañas de prensa difamatorias, el rumor e incluso la violencia y el terrorismo. El buen político no debe vivir de espaldas al mal que le rodea, sino enfrentarlo con cautela y fortaleza.

Todos los elementos que hemos reseñado se subordinan a la cualidad más importante en el orden de la prudencia: la providencia o capacidad de tener siempre a la vista el fin que se persigue ${ }^{32}$. De este modo, se pueden ordenar a él los medios oportunos previendo las consecuencias que pueden seguirse de las diversas acciones políticas. Aquí se encuentra el núcleo de la actuación política prudente: poner los medios lícitos y eficaces para acceder al poder; utilizar el poder -o influir en él- en orden al bien común.

\section{Las funciones de la actividad política}

Nos hemos referido ya a la naturaleza de la actividad política. Ahora encontramos que los actos de la prudencia (en cuanto virtud moral del político) se corresponden con las funciones que desempeña en la práctica la actividad política considerada como profesión específica. Estos actos son tres: el consejo o deliberación, el juicio y el imperio $^{33}$.

En primer lugar, los políticos prudentés dèliberán y averiguan acerca de las circunstancias en que desempeñan su actividad y acerca de los medios que puedan resultar útiles y buenos moralmente para alcanzar un fin propuesto. Esta actividad está en la naturaleza de la política como arte de lo contingente. Para un solo hombre es imposible conocer todos los aspectos de una cuestión. Debe aconsejarse, consultar, deliberar junto con otros ${ }^{34}$. Esta función de la prudencia muestra que la política es y debe ser una obra colectiva, de varios hombres que se empeñan en lo mismo, con una sana lógica de la controversia y de la discrepancia. Desde un punto de vista externo, es fácil apreciar que gran parte de la actividad política consiste en confrontar opiniones, programas, etc. El debate político es una exigencia ética de prudencia, aunque no lo sea cada debate en particular. El político prudente no debe, por lo general, rehuir los debates o la confrontación de opiniones por diversos medios; sin embargo, bien pueden evitarse determinados debates previsiblemente contraproducentes, o en los que no se dan las condiciones para un diálogo respetuoso, o en los que no se conceden iguales condiciones de manera imparcial a los participantes. En la duda, nos parece más razonable optar por el diálogo.

El resultado de la deliberación, del diálogo y de los consejos recibidos es un cúmulo de antecedentes e informaciones a menudo contradictorios entre sí. A partir de ellos, en segundo lugar, la misma prudencia lleva a emitir un juicio conjetural, de carácter personal (opinión de un político) o colectivo (posición oficial de un grupo, asociación o partido político). Formarse una opinión personal, con libertad y responsabilidad, también es una exigencia ética. Cualquier ciudadano debe tenerla sobre las cuestiones públicas consideradas desde un punto de vista global. Esta obligación tiene un contenido y una fuerza muy variable dependiendo de la diversidad de circunstancias persona-

\footnotetext{
${ }^{32}$ Cfr. S. Th., II-II, q. 49, a. 6.

${ }^{33}$ Santo Tomás afirma que la recta ordenación de los medios al fin requiere la rectitud del consejo, del juicio y del imperio, sin los cuales no puede darse una correcta ordenación hacia el fin (S. Th., II-II, q. 49, a. 6, ad. 3).

${ }^{34}$ Cfr. S. Th., II-II, q. 47, a. 8, resp., y, además, S. Th., II-II, q. 51, aa. 1 y 2 , sobre la eubulia o virtud de aconsejar bien.
} 
les. Con todo, es un deber de especial importancia para los profesionales de la política, aunque también aquí hay diferencias: unos políticos estudian más a fondo las cuestiones económicas; otros, las educacionales; o las legislativas y constitucionales; o las diplomáticas, de defensa, etcétera, etcétera.

La función de juzgar no va unida necesariamente al debate, pero sí a una deliberación y estudio previos. Sin estudio no se puede opinar responsablemente. De más está insistir en el deber de estudiar, pues cualquiera advierte con facilidad el penoso papel que representa un político que opina sin conocimiento de causa, o con un conocimiento tan genérico y superficial que a duras penas disimula la ignorancia ${ }^{35}$.

Finalmente, es propio de la política imperar. Este es el acto principal de la prudencia ${ }^{36}$, por lo cual los políticos no gobernantes buscan como fin de sus actuaciones influir en el poder. Nadie se contenta con emitir su opinión y dejar que la aproveche quien buenamente lo desee. La idea es otra: lo que se ha juzgado prudente para resolver tal o cual problema público debe ser puesto en práctica. Es inseparable de la política - de una política rectamente entendida, prudente - hacer exigencias a la autoridad, ejerciendo una legítima influencia en la conducción de los asuntos públicos, siempre dentro del respeto y la moderación. Ya hemos dicho que este deber de prudencia se cumple ejercitando los derechos de petición, libertad de expresión, reunión, sufragio cuando corresponda, etc.

Esta función de imperar sólo podrá cumplirse a cabalidad desde el gobierno. Por tanto, la misma dinámica interna de la política exige que se busque acceder al poder ${ }^{37}$. La prudencia presenta el acceso al poder como el medio fundamental para realizar lo que la misma prudencia juzga e impera como bueno. El deseo de poder, por tanto, es moralmente lícito. No es manifestación de egoísmo o soberbia aspirar a ocupar los cargos públicos. En determinadas circunstancias puede llegar a ser obligatorio.

La función de imperio se realiza, sobre todo, en el acto de legislar ${ }^{38}$, pues la ley es el modo de imperar sobre los miembros de la sociedad dirigiéndolos hacia el bien común $^{39}$. La función política legislativa radicada en un Parlamento constituye una institucionalización de los actos de la prudencia política: se delibera, se discute, se debate, se reciben consejos e informes técnicos; cada parlamentario forma su juicio; a través de la votación, se aprueba un juicio colectivo; finalmente, se convierte en acto de imperio mediante la promulgación de la ley. Las varias etapas en el proceso de forma-

35 Vid. S. Th., II-II, q. 51, a. 3 (sobre la synesis o virtud de juzgar bien, con sensatez); y a. 4 (sobre la gnome o virtud de juzgar con
perspicacia en situaciones de excepción).
36 Cfr. S. Th., II-II, q. 47, a. 8.
${ }^{37}$ Estamos pensando en el régimen democrático, donde la forma de gobierno implica acceso legal al poder.
38 No pensamos, con todo, que la ley sea todo el derecho ni que el derecho se reduzca a ser un mandato del poder. Al contrario,
cuando el poder está institucionalizado el mismo derecho lo limita: "Los hombres del Poder se sienten comprometidos con un
gran sistema de obligaciones. El Derecho se les impone, y ellos no pueden actuar más que por sus caminos" (Bertrand de Jou-
venel: El Poder. Historia Natural de su Crecimiento (Madrid, Ed. Nacional, 1956) p. 243; vid., en general, pp.241-243, 326-346
y 352 ).
39 Cfr. S. Th., II-II, q. 47, aa. 10, 11 y 12. 
ción de las leyes, reguladas constitucional y legalmente en diversos ordenamientos jurídicos, garantizan el carácter democrático y prudencial de la actividad legislativa ${ }^{40}$.

El mismo fenómeno de institucionalización de la prudencia se da en todos los órganos de gobierno colegiales, en la organización y funcionamiento del gabinete presidencial o del Primer Ministro, etc.

\section{La negación de la prudencia}

Santo Tomás de Aquino distingue los vicios que contradicen manifiestamente la prudencia - falta la misma prudencia o alguno de sus requisitos- de aquellos otros vicios que poseen cierta similitud falsa con la prudencia y que proceden de un abuso de las habilidades requeridas por ella ${ }^{41}$. Un político puede incurrir tanto en los defectos que se oponen directamente a la prudencia como en los que la contrarían aunque se le parecen en algún aspecto.

En primer lugar, se puede obrar precipitadamente por falta de buen consejo y deliberación. Así ocurre cuando el político se considera autosuficiente, evita los debates, no escucha las opiniones ajenas, etc. ${ }^{42}$. La precipitación implica moverse a actuar por el ímpetu de la pasión o de la voluntad sin pasar por etapas intermedias, cuales son: "memoria de las cosas pasadas, inteligencia respecto de las presentes, sagacidad para considerar los eventos futuros, ponderación razonable de las alternativas, docilidad para aceptar los consejos de gente experimentada" ${ }^{43}$.

También se puede juzgar sin considerar suficientemente todas las circunstancias del caso o los consejos y antecedentes reunidos; es decir, a pesar de recibir buenos consejos y de reflexionar, se falla en el juicio ${ }^{44}$. Los políticos que se contradicen en sus opiniones manifiestan una cierta inconsideración, porque la contradicción emana de considerar algunas veces un aspecto de la cuestión y otras veces otro, sin verla nunca en forma completa. La contradicción de las propias opiniones es un defecto de lógica, pero su causa es la falta de prudencia.

No debe confundirse, empero, la contradicción con un cambio prudente y consciente de opinión. No es lo mismo sostener a la vez y respecto de idéntica cuestión dos tesis contradictorias, que corregir y rectificar un juicio después de recibir nuevos antecedentes o de pensar mejor las cosas. Esta última actitud es una manifestación patente de prudencia y de humildad. La capacidad de rectificar hace posible que el diálogo político fructifique, desterrando cualquier rigidez en materias que por su índole propia son opinables, variables y contingentes.

Finalmente, puede fallarse en el imperio cuando por negligencia no se impera ${ }^{45}$ o se es inconstante ${ }^{46}$ en poner por obra lo que se ha imperado. Hay negligencia cuando no

\footnotetext{
40 C.P.R. de 1980 , arts. 62 a 72.

${ }^{41}$ Cfr. S. Th., II-II, q. 53, introducción.

${ }^{42}$ Cfr. S. Th., II-II, q. 53, a. 3, resp.

${ }^{43}$ Ibidem.

${ }^{44}$ Cfr. S. Th., II-II, q. 53, a. 4.

${ }^{45}$ Cfr, S. Th., II-II, q. 54.

${ }^{46}$ S. Th., II-II, q. 54 , a. 5.
} 
se toman las decisiones políticas oportunas, o no se hacen a la autoridad las peticiones necesarias, o no se aprueban las leyes, etc. Es inconstante el político que se propone determinadas acciones y luego sólo las realiza esporádicamente, abandona su estrategia, etc.

Ciertamente es difícil encontrar en los políticos defectos como la pereza o la indolencia o negligencia cuando se trata de luchar por el poder (o por intereses privados defendidos desde las esferas del poder público). En cambio, no ocurre así cuando se trata de trabajar esforzadamente por el bien común, estudiando y colaborando activamente con la autoridad, aun sin esperar como fruto el acceso al poder. La diferencia, a nuestro juicio, estriba en que la actividad por el poder se encuentra estimulada, al menos, por la necesidad de realizar los propios proyectos; $y$, muy frecuentemente, por una pasión que en sí misma no es mala, pero que fácilmente degenera en puro deseo de dominio. La solicitud por el bien común, por el contrario, sólo puede proceder de virtudes como la caridad y la justicia, cuya adquisición y práctica exigen esfuerzo.

La perversión del orden de los medios a los fines lleva a actitudes que parecen prudencia y no lo son ${ }^{47}$. Existe la habilidad de encontrar medios técnicamente eficaces para satisfacer el ansia de poder, para acceder a los cargos o desplazar a los adversarios. Se pone el poder como fin último. Este defecto es patente en el tirano, y debemos considerar que tirano no es sólo el que detenta un poder absoluto y sin contrapeso, sino todo el que desarrolla en la práctica conductas orientadas a obtener una dominación de tal tipo para sí mismo o para un grupo o partido. Las conductas tiránicas aparecen en muchos políticos, pues sólo un fundamento moral puede contrarrestarlas. Lo más peligroso de esta actitud es que, dada su eficacia para el logro de los objetivos propuestos, puede confundirse con la prudencia como virtud (el tirano conoce los medios disponibles y sabe usarlos) ${ }^{48}$.

Otro defecto consiste en saber utilizar la simulación, el fraude o el dolo para conseguir los fines propuestos ${ }^{49}$. En este caso, aunque el fin sea bueno la utilización de medios malos pervierte la acción globalmente, pues nunca se justifica el engaño a través de las palabras o de los hechos. El vicio que comentamos no es tan grave como el anterior, pues no necesariamente implica la absolutización del deseo de poder puesto como fin último; solamente se trata de una desviación en el uso de los medios.

Aquí se incluye la demagogia política, esa habilidad para ganar popularidad en base a promesas imposibles de cumplir o mediante la realización de hechos - medidas económicas, por ejemplo- que dan una apariencia de mayor bienestar, aunque a la postre causen un retroceso. La demagogia se ha demostrado históricamente efectiva como medio de acceso al poder, sobre todo en países de poco desarrollo cultural y cívico. Cabe entonces preguntarse si es lícito acudir a ella para contrarrestar las campañas de los adversarios políticos, sobre todo cuando se trata de personas con programas de gobierno claramente inmorales o totalitarios. La misma prudencia exige poner todos los

${ }^{47}$ Cfr. S. Th. II-II, q. 55. Santo Tomás considera, por vía ejemplar, que un ladrón puede llamarse "prudente" porque descubre formas convenientes de robar; pero esta prudencia es falsa (cfr. S. Th., II-II, q. 47, a. 13, resp.)

${ }^{48}$ Cfr. S. Th., II-II, q. 55, aa, 1 y 2.

${ }^{49}$ Cfr. S. Th., II-II, q. 55, aa. 3, 4 y 5. 
medios lícitos - tal es la cuestión difícil de conocer, la licitud - para evitar que el poder político caiga en manos de individuos inescrupulosos.

La respuesta, a mi juicio, no es unívoca. Podemos distinguir dos tipos de "demagogia". En ocasiones es difícil juzgar si una actitud constituye una demagogia "buena" o "mala". En principio es lícito recurrir a las técnicas publicitarias y a los recursos retóricos, buscando llegar no sólo a la inteligencia de los electores sino también a su sensibilidad. No hay inconveniente en asegurar la defensa de determinados objetivos e ideales, aun sabiendo que no son plenamente alcanzables, porque a nadie se engaña al hablar de las grandes metas y aspiraciones. Sin embargo, cuando entramos al terreno de las promesas concretas, avaladas por medidas y por plazos, las palabras deben estar respaldadas en posibilidades reales.

El límite entre la demagogia buena y la mala es el que existe entre la simple idealización y la mentira. Las exageraciones retóricas o los eslóganes políticos equivalentes a las medidas publicitarias lícitas en cualquier negocio forman parte de una política normal, sana, que por ser humana no puede consistir en una fría racionalidad. Las pasiones existen y operan en política. La moral no busca su eliminación, sino su adecuado control y encauzamiento. En cambio, el auténtico dolo, la maquinación fraudulenta destinada a obtener la adhesión de las voluntades ciudadanas ${ }^{50}$, no es lícito bajo ningún aspecto.

En resumen: ni tanta demagogia que engañe al pueblo, ni tan poca que lo paralice. También en la política es bueno soñar y hacer soñar; tener grandes deseos y entusiasmar a otros hombres para emprender la realización de un proyecto político con espíritu de aventura. Pero los sueños no deben llevar al adormecimiento de las masas ni al ensueño utópico de los deseos ineficaces.

50 En el ámbito jurídico se ha definido el dolo en cuanto vicio de la voluntad como aquella "maquinación fraudulenta destinada a que una persona preste su consentimiento para la celebración de un acto o contrato" (Víctor Vial del Río y Alberto Lyon Puelma: Derecho Civil. Teoría General de los Actos Jurídicos y de las Personas. (Santiago, Ed. Universidad Católica, $1^{\text {}}$ ed., 1985) p. 69). Recordemos que las nociones generales del Derecho Civil constituyen elementos básicos de todas las ramas del Derecho, tanto privado como público, no obstante las adaptaciones específicas de cada caso. En este sentido, el apoyo popular (consentimiento público) obtenido mediante demagogia fraudulenta (dolo) adolece de un vicio que puede afectar en mayor o menor medida la legitimidad (validez) de la representación popular. Ahora bien, la legitimidad de la representación popular no afecta directamente la legitimidad del gobierno en cuanto a su origen o ejercicio, aunque puede llegar a tales extremos. En cualquier caso, queda menoscabado el carácter democrático de los políticos implicados, sean o no gobernantes. Si la democracia es el gobierno del pueblo, por el pueblo y para el pueblo, ¿qué puede ser más antidemocrático que engañar al pueblo mismo? 